\title{
Jet-Impingement Effects of Alumina-Nanofluid on Aluminum and Copper
}

\author{
Gustavo J. Molina, Fnu Aktaruzzaman, Whitney Stregles, \\ Valentin Soloiu, and Mosfequr Rahman \\ Department of Mechanical Engineering, Georgia Southern University, Statesboro, GA 30458-8046, USA \\ Correspondence should be addressed to Gustavo J. Molina; gmolina@georgiasouthern.edu
}

Received 29 May 2014; Accepted 5 August 2014; Published 21 August 2014

Academic Editor: Meng Hua

Copyright @ 2014 Gustavo J. Molina et al. This is an open access article distributed under the Creative Commons Attribution License, which permits unrestricted use, distribution, and reproduction in any medium, provided the original work is properly cited.

\begin{abstract}
Nanofluids are nanosize-powder suspensions that are of interest for their enhanced thermal transport properties. They are studied as promising alternatives to ordinary cooling fluids, but the tribiological effects of nanofluids on cooling-system materials are largely unknown. The authors have developed methodology that uses jet impingement on typical cooling-system materials to test such effects. The work is presented of the authors' research on the interactions of a typical nanofluid ( $2 \%$ volume of alumina nanopowders in a solution of ethylene glycol in water) which is impinged on aluminum and copper specimens for tests as long as 112 hours. The surface changes were assessed by roughness measurements and optical-microscope studies. Comparative roughness indicate that both the reference cooling fluid of ethylene glycol and water and its nanofluid with $2 \%$ alumina produce roughness changes in aluminum (even for the shortest 3-hour test), but no significant roughness differences were observed between them. No significant roughness changes were observed for copper. Microscopy observations, however, show different surface modifications in both aluminum and copper by both the nanofluid and its base fluid. The possible mechanisms of early erosion are discussed. These investigations demonstrate suitable methods for the testing of nanofluid effects on cooling system-materials.
\end{abstract}

\section{Introduction and Literature Review}

The concept of nanofluid was proposed in 1995 by Choi and Eastman [1] and Choi [2] as a suspension of solid nanosize (1 to 100 nanometers) particles in a carrier liquid. Since then, nanofluids have been produced for many research purposes as mixtures (typically up to 5\%) of solid metal nanoparticles (as gold), oxides (as alumina, silica, titanium dioxide, and copper oxide), carbides, or nitrides nanoparticles and of carbon nanotubes or nanofibers in continuous and saturated fluids (as water, ethanol, and ethylene glycol) [3]. Nanofluids are predicted to have higher thermal conductivity and heat transfer coefficients than those of the base fluids because solids have much larger thermal conductivity than those of carrier fluids, and nanoparticles have a much larger surfaceto-volume ratio and larger mobility than those of larger solid particles. Therefore, nanofluids are promising as coolants for critical-cooling systems, as nuclear systems [4], large engine radiators, and microchips [5]. These and other potential uses of nanofluids, as applications for enhanced detergency, in the biomedical field, and as smart fluids, were discussed by Wong and De Leon [5]. Synthesis of nanopowders, preparation of nanofluids, and nanofluid performance as transport- and electromagnetically active-media and as media for chemical reactions have been recently reviewed by Taylor et al. [6].

Thermal and transport properties of nanofluids are predicted as substantially different from those of the base fluids, such as their increased thermal conductivity [7] and larger viscosity than those of the base fluids [7], and an abnormal convective-heat-transfer coefficient $[8,9]$. Measurements of nanofluids' effective thermal conductivity and viscosity found them to be substantially higher than those of the base fluids [10]. The enhancement of heat transfer coefficient appears to go beyond a mere thermal-conductivity effect because it cannot be predicted by traditional pure fluid correlations. These abnormal thermal properties may be partially explained by the very large surface to volume ratio and high mobility nanosize particles $[7,9]$, but a full 
understanding of nanofluid thermal properties should also consider the thermal dispersion and intensified turbulence brought about by nanoparticle motion [4]. The measured thermal conductivities of nanofluids strongly depend on temperature, particle volume fraction, size, shape [9], coating of nanoparticles [11], type of base fluid [12], and $\mathrm{pH}$ of mixtures [13]. Such dependences and some larger than expected nanofluid viscosities can be partially explained [1416] by aggregation of the nanoparticles, while the kinetics of deagglomeration may strongly depend also on suspension of $\mathrm{pH}$ [17]. A comprehensive review of heat transfer properties of nanofluids and their dependence on several factors was presented by Das et al. [18].

The potential of nanofluids to enhance existing heatexchanger systems has prompted experimental work with traditional radiators. For instance, Leong et al. [19] reported the heat transfer enhancement of an automotive car radiator using ethylene glycol with $2 \%$ copper as nanofluid (with ethylene glycol as the base fluid for comparison); they observed that the overall heat transfer coefficient and bulk heat transfer increased by about $3.8 \%$ with the use of the nanofluid compared to the base fluid alone. The work of Peyghambarzadeh et al. [20] tested five different concentrations for nanofluid of alumina nanoparticles in water in the range of 0.1 to $1 \%$ volume, as they compare to pure water in an automobile radiator. Their results demonstrated that the nanofluids with those low concentrations can enhance heat transfer efficiency up to $45 \%$ in comparison to pure water. Some follow-up work by the same researchers [21] measured the overall heat transfer coefficient (according to the conventional 3NTU technique) in a car radiator cooled by copper-oxideand iron-oxide-nanofluids at concentrations of $0.15,0.4$, and 0.65 vol. $\%$ in water. They found that both nanofluids produced larger overall heat transfer coefficients (by up to 9\%) as compared to those for water and that increasing the nanoparticle concentration enhanced the heat transfer. However, increasing the nanofluid inlet temperature led to lower overall heat transfer. A computational fluid dynamics simulation [22] of ideal nanofluid cooling in a Cummins $500 \mathrm{hp}$ diesel engine showed that radiator size could be reduced by $5 \%$.

Many concerns remain about nanofluid effects on cooling-system materials, particularly wear and erosion, and there is little understanding of the tribological impact of nanofluids on typical material surfaces. Initial research at the US Department of Energy facilities [23] suggested that no surface change would result to aluminum 3003 jet-impacted by a $\mathrm{SiC}$-nanofluid jet, for the case of 750 hours of a 2 vol.\% $\mathrm{SiC}$ in water nanofluid at $8 \mathrm{~m} / \mathrm{s}$ and impact angle of $30^{\circ}$. The follow-up work of Singh [24] with the same methods found no significant erosion using nanofluids of $\mathrm{Cu}$ and $\mathrm{Al}$ oxides in the base fluids ethylene and trichloroethylene glycols, with velocities of $9 \mathrm{~m} / \mathrm{s}$ and at $90^{\circ}$ and $30^{\circ}$ impact angles: the corresponding erosion rate in vehicle radiator was extrapolated to be of 0.065 milligrams/year of typical vehicle operation. Nguyen et al. [25] reported the wear effect on an aluminum specimen subjected to the impinging of a jet of a $5 \%$ alumina-in-water nanofluid at a velocity of $9.6 \mathrm{~m} / \mathrm{s}$. After 180 hours, a significant total mass loss of $14 \mathrm{mg}$ was measured.
Recent experimental research work [26, 27] tested the material-removal effects on aluminum, copper, and stainless steel targets of nanofluid jets of $\mathrm{TiO}_{2}, \mathrm{Al}_{2} \mathrm{O}_{3}$, and $\mathrm{ZrO}_{2}$ (each at $9 \%$ concentration) and of $\mathrm{SiC}$ (at $3 \%$ concentration) in the base fluid of distilled water plus a surfactant, as they compared to the same materials impacted by a water-only jet. They measured target thickness differences by scanning the surface with a profilometer as an estimation of the wear. While no differences in erosion effects were observed for stainless steel, some significant increases of erosion (as compared to base fluid) were observed on aluminum targets for the $\mathrm{TiO}_{2}, \mathrm{Al}_{2} \mathrm{O}_{3}$, and $\mathrm{ZrO}_{2}$ nanofluids (of about three hundred times the wear removal caused by water) and for copper only in the case of $\mathrm{ZrO}_{2}$ nanofluid. No effects were observed for any target material when impacted by the SiC nanofluid. From SEM analysis they concluded that, for the used nanofluids, most of the material would be removed by mechanical erosion, while,for the water, it would be worn mainly by intergranular corrosion (around the impurities of the metal matrix); $\mathrm{SiC}$ seemed to cause a very small corrosion effect, partly counterbalanced in the wear removal measurement by a deposition of metal oxides.

George et al. [28] recently presented experimental work on erosion effects of a nanofluid of $0.1 \%$-volume of $\mathrm{TiO}_{2}$ in distilled water. They tested for up to 10 hours the jetimpingement effects at different angles on aluminum and cast iron surfaces, by measuring weight loss, roughness by speckle interferometry, and hardness after tests. Employed jet speeds were $5 \mathrm{~m} / \mathrm{sec}$ and $10 \mathrm{~m} / \mathrm{sec}$. They found that the rates of erosion reached maxima at a $20^{\circ}$ angle of impingement for aluminum and at a $90^{\circ}$ angle for cast iron. SEM images and AFM scans were used to identify likely mechanisms of erosion: corrosion-assisted erosion was the prominent mode of material removal in cast iron, whereas mild abrasive erosion was responsible for the observed aluminum smoothening upon nanofluid impingement; some degree of work hardening was observed for both materials.

The authors presented [29] some preliminary work about the effects of jet-impingement on the roughness change ( $\mathrm{Ra}$, $\mathrm{Rz}$, and $\mathrm{Rq}$ ) of 3003-T3 aluminum and copper specimens after 3-, 7-, and 14-hour treatments with suspensions of $2 \%$ nanoalumina in water and in a solution of water plus ethylene glycol, as they compared to average initial roughness. Some substantial increases of roughness were found for the aluminum specimens, while no significant change was observed for copper. They also presented [30] dynamic viscosity measurements, showing that the addition of $2 \%$-volume of alumina nanopowders in ethylene glycol increased viscosity by about $30 \%$, while a $5 \%$ of nanopowder can almost triple the viscosity. The authors concluded that a $2 \%$-volume concentration seemed to be a reasonable practical compromise (to enhance overall efficiency of cooling systems) between the likely improvements of heat transfer versus the increased viscosity. This paper presents the authors' recent work on wear and erosion effects of alumina-nanopowder-nanofluid jet-impingement on two typical cooling-system materials, aluminum and copper, for long experiments (up to 112hour tests), including microscopy analysis of the impacted 
surfaces, and discussion of possible mechanisms of surface modification.

\section{Experimental Methods and Test Parameters}

The authors developed a test rig to explore the possible erosion effects of some typical nanofluid suspensions impacting some typical cooling-system materials. Figure 1 shows a schematic and a photograph of the developed test rig.

The test rig of Figure 1 allows controlling a fluid jet, which impacts a material target (the test specimen); nozzle to target distance and target angle can be set within wide ranges; nanofluid is recirculated by the instrument pump during each test; development of the instrument is presented elsewhere $[29,30]$. The recirculation (gear) pump yields a maximum volume flow of $2.5 \mathrm{liter} / \mathrm{minute}$ at nozzle velocity of $10.7 \mathrm{~m} / \mathrm{s}$. The tests of this research work employed a commercial mixture of ethylene glycol in water (Prestone Super Tech 50/50 antifreeze/coolant [31]) as reference fluid and the nanofluid suspension obtained by adding a $2 \%$ volume concentration of alumina nanoparticles in that reference fluid. This mixture was formulated from a $20 \%$-aluminum-oxide nanopowder dispersion in water (in which the employed nanopowders were of $99.99 \%$ gamma-alumina, $10 \mathrm{~nm}$ original average particle size before aggregation in a $20 \%$ dispersion, proprietary dispersant not disclosed, supplied by US Research Nanomaterials, Inc).

The jet-impingement tests were carried out for 3, 7, 14, 28,56 , and 112 hours for each of the fluids, where fluid jets were applied normally (e.g., at $90^{\circ}$ ) to test specimen surfaces, for constant distance from nozzle to target of 1 inch $(25.4 \mathrm{~mm})$. Test target materials were copper alloy 110 (99.90\% electrolytic heat exchanger quality, supplied by MSC Inc.) and aluminum 3003-T3 alloy (supplied by Kaiser Aluminum); each specimen was a plate of 3 inch by 2 inch ( $50.8 \mathrm{~mm}$ by $75.4 \mathrm{~mm}), 0.05$ inch $(1.27 \mathrm{~mm})$ thickness.

Each specimen was polished using flexible sand paper with distilled water in the sequence of 220,800, and 1200 grit, to obtain a Ra roughness not greater than $7 \mu$ inch. Specimens were cleaned before tests by ultrasonic method with micro90 cleaning solution, and they were rinsed with distilled water after tests and air-dried before weight and roughness measurements, which were performed before and after tests. Assessment of material-removal was carried out by pre- and posttest weighing of specimens, with a Shimadzu AUW120D balance of $0.1 \mathrm{mg}$ minimum readability in the used range.

Further assessment of surface modifications was carried out by pre- and posttest roughness measurements; the employed instrument was a Mitutoyo Surfest SJ-201 surface roughness tester, and the recorded roughness parameters were $\mathrm{Ra}, \mathrm{Rq}$, and $\mathrm{Rz}$. Roughness was measured in two directions: along the lay (e.g., the predominant polishing direction) and across it. For the employed measurement range of $14,400 \mu$ inch $(360 \mu \mathrm{m})$, the instrument resolution was of $1 \mu$ inch $(0.0254 \mu \mathrm{m})$ [32].

Optical microscopy observations were also carried out for the impacted material surfaces (of aluminum and copper specimens) before and after the jet-impingement tests to assess surface modifications and to help elucidate the mechanisms of material change. A Keyence VHX 1000 Digital Microscope of 54 Megapixel resolution was used. Surface images were captured by a high resolution zoom lens $\mathrm{VH}-\mathrm{Z} 500 \mathrm{R} / \mathrm{W}$ for magnifications of 500x to 5000x (in the sequence 500x, 1000x, 2000x, 3000x, and 5000x). A lower resolution lens (VH-Z20R) also was used at magnifications of 20x to 200x (in the sequence 20x, 30x, 50x, 100x, 150x, and 200x). A VH-Z20R lens was employed for capturing images by three other lens angles $\left(15^{\circ}, 45^{\circ}\right.$, and $\left.90^{\circ}\right)$.

\section{Results and Discussion}

Figure 2 presents the measured average Ra roughness for 3003-T3 aluminum specimens before and after 3-, 7-, 14-, 28-, 56-, and 112-hour treatments with (i) the reference fluid of 50/50\% ethylene glycol in water (EG/Water) and (ii) a nanofluid of $2 \%$-volume of nanoalumina mixed in the reference fluid (initial values (without treatment) are called "before test," while values after each treatment are called "after test" in following graphs).

The measurements presented in Figure 2 indicate that aluminum-specimen roughness is affected by the jetimpingements with both the reference fluid (EG/water) and its 2\%-alumina-nanofluid. For both of them, the Ra roughness values initially decrease (from the 3-hour test) showing relatively lower values for 7 and 14 hours, to be followed by a monotonous increase after 28 hours (and longer) of testing. Similar trends were observed for the two other measured roughness parameters, $\mathrm{Rq}$ and Rz. Weight measurements suggested a small increase in weight after treatments (the highest measured of $5 \mathrm{mg}$ ) for 3- to 28-hour tests on aluminum, but no significant weight change was observed after 28 hours of jet-impingement.

Since the initial roughness for each specimen presented in Figure 2 was within the 2- to 7-microinch range, each of the $\mathrm{Ra}$ values is normalized and presented in Figure 3. Normalization of each after-test Ra-value was done by dividing it by the corresponding initial (before-test) Ra for the corresponding specimen. Figure 3 clearly shows the trends suggested by Figure 2, of initial roughness increase, followed by a decrease for 7 and 14 hours and by a monotonous increase after 28 hours of test. The roughness values increase up to eightfold for the longest tested time of 112 hours. The evolution of roughness in Figures 2 and 3 suggests that some early cleaning of the surface may occur during the first three hours of test (shown as a small increase of roughness), while removal of loose material (left from previous polishing) occurs within the first 14 hours. After 28 hours of test, increased material erosion seems to proceed. Figure 3 also suggests that there were no significant differences on the measured roughness values after jet-impingement by the reference fluid (ethylene glycol/water), compared to those by its $2 \%$-alumina-nanofluid.

The measured roughness changes for aluminum samples suggest that significant surface modifications occur when impinged by a jet of the tested fluids. To study such modifications, optical microscopy was conducted for all 

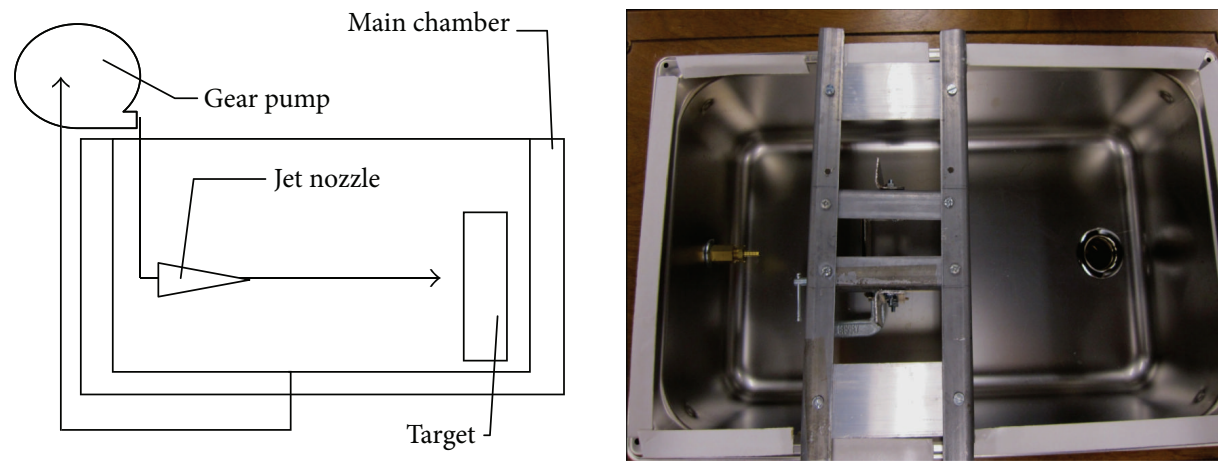

FIGURE 1: Schematics and photograph of the authors' test rig to assess nanofluid wear.

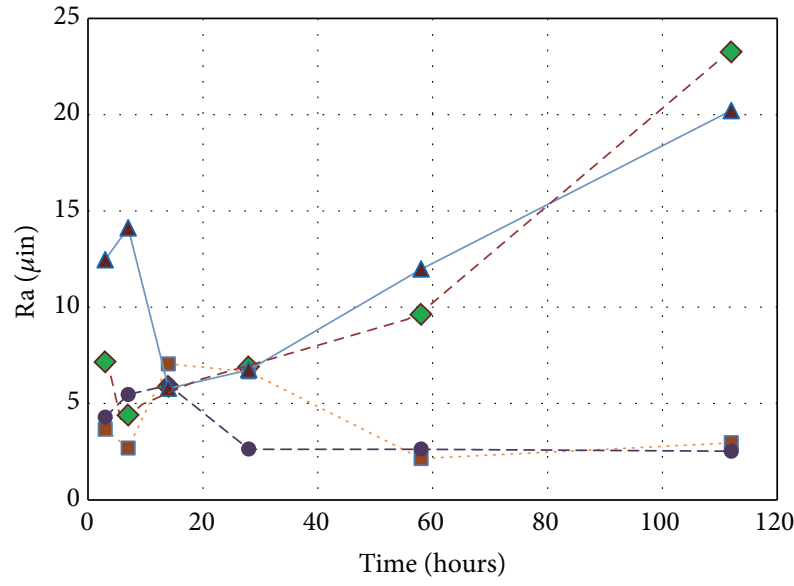

- Average Ra before test without nanoparticle
$-\checkmark-$ Average Ra after test without nanoparticle
- - Average Ra before test with nanoparticle
- Average Ra after test with nanoparticle

Figure 2: Average Ra roughness for 3003-T3 aluminum before and after 3-, 7-, 14-, 28-, 56-, and 112-hour treatments with the reference fluid of 50/50\% ethylene glycol in water and with nanofluid of $2 \%$ nanoalumina in reference fluid.

the specimens after and before treatments. Figures 4 and 5 show microscopy images (for 5000x magnification) for the aluminum specimens before and after jet-treatments with each corresponding fluid.

Figure 4 allows comparison of before- and after-test images with reference fluid of 50/50\% ethylene glycol and water (magnification: 5000x) without nanoparticles. After treatment, polishing scratches have been removed (after test of 112 hours), and small pitting on average, smaller than 5 micrometers (200 microinches) becomes larger (to average of 5 to 10 micrometers (200 to 400 microinches), showing as circled darker clusters in after-test image); some observed features also suggest that some larger areas (of about 20 micrometers, not shown in Figure 4) may have started some "spalling."

Figure 5 allows comparison of before- and after-test images with nanofluid of $2 \%$ alumina in 50/50\% ethylene glycol and water (magnification: 5000x). After 112-hour

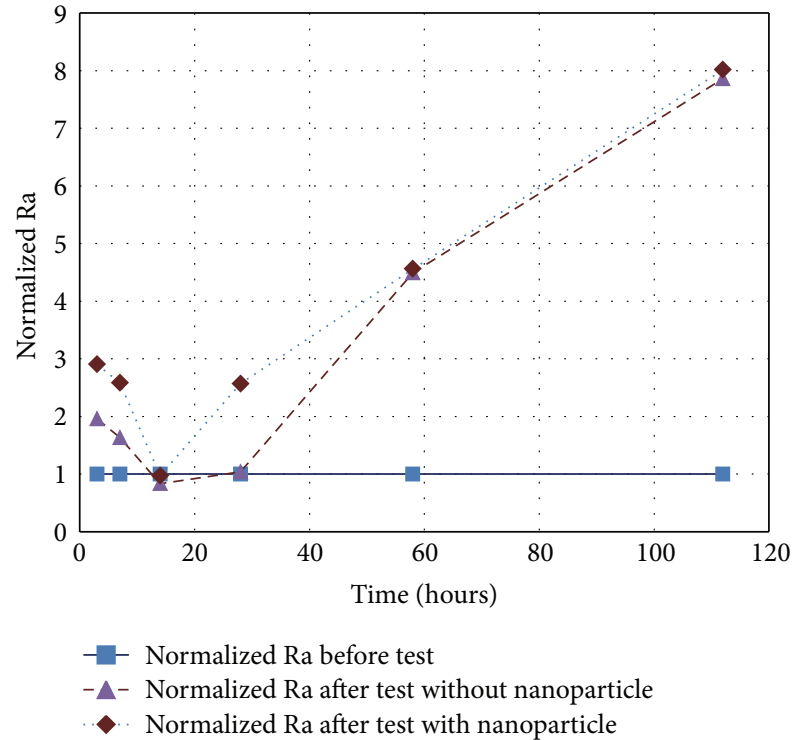

FIGURE 3: Normalized Ra roughness for 3003-T3 aluminum before and after 3-, 7-, 14-, 28-, 56-, and 112-hour treatments with the reference fluid of 50/50\% Ethylene glycol in water and with nanofluid of $2 \%$ nanoalumina in reference fluid.

treatment, some polishing scratches remain (as compared to Figure 4 images, where scratches were fully removed), and small pitting size is widespread (on average, smaller than 5 micrometers (200 microinches, circled in the figure) and pitting seems like clusters along original scratching lines (circled in the figure).

Figure 6 presents the typically measured average $\mathrm{Ra}$ roughness for copper alloy 110 before and after 3-, 7-, 14, 28-, 56-, and 112-hour treatments with (i) the reference fluid of $50 \%$ ehtylene glycol in water (EG/Water) and (ii) a nanofluid of $2 \%$ volume of nanoalumina mixed in the reference fluid (initial values (without treatment) are called "before test," while values after each treatment are called "after test" in following graphs). Since the initial roughness for each specimen presented in Figure 6 was within the 2to 4 -microinch range, each of the Ra values is normalized and presented in Figure 7, where normalization of each aftertest Ra-value was done as for data of Figure 3. Measured 

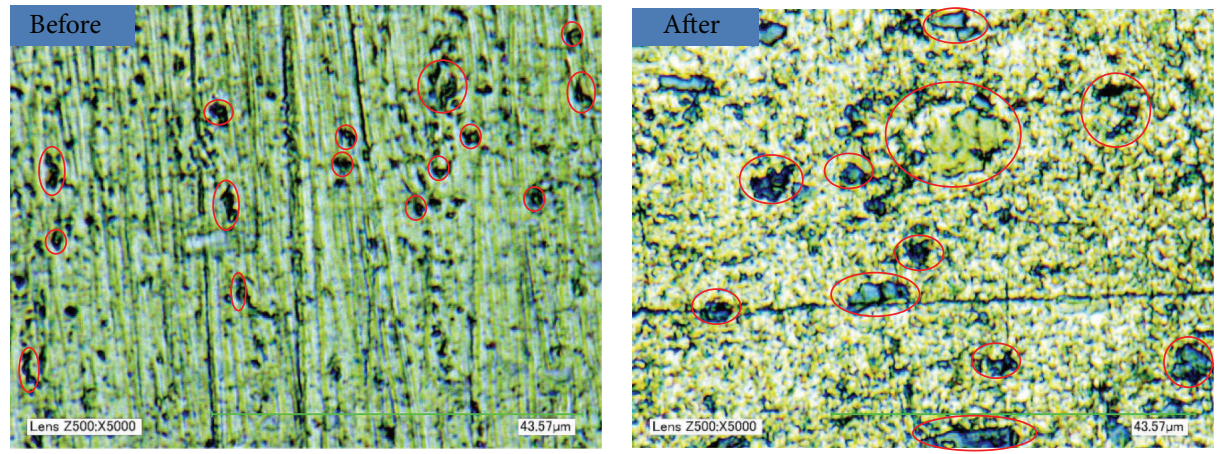

FIGURE 4: Optical microscopy images of 3003-T3 aluminum before and after (112-hour) test with (reference fluid, without nanoparticles) 50/50\% ethylene glycol/water (magnification: 5000x). Preexisting pitting and enlarged ones after treatment are circled.
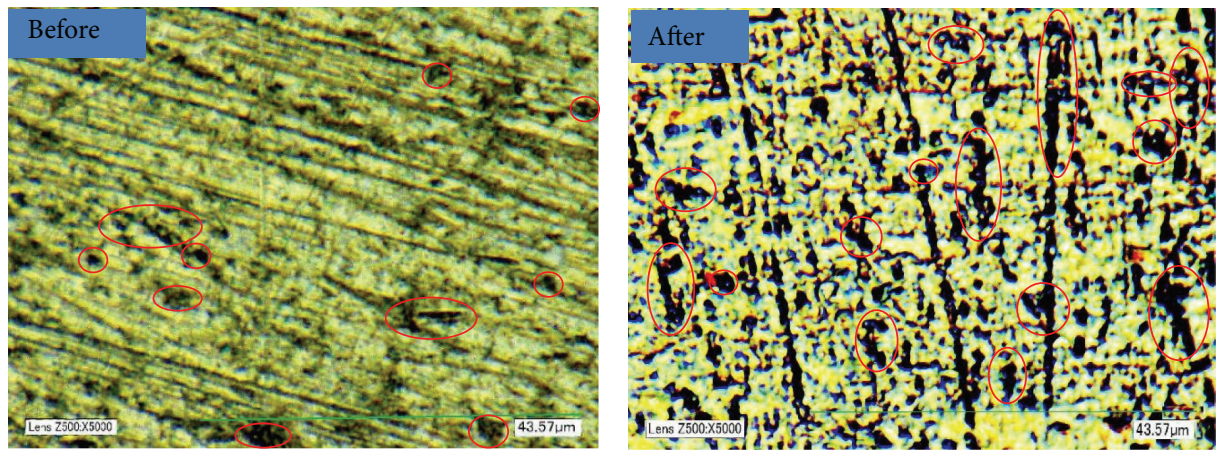

Figure 5: Optical microscopy images of 3003-T3 aluminum before and after (112-hour) test with nanofluid of 2\% alumina in 50/50\% ethylene glycol/water (magnification: 5000x). Preexisting pitting and enlarged ones after treatment are circled.

$\mathrm{Rq}$ and $\mathrm{Rz}$ roughness showed similar trends. No significant roughness differences were measured, but normalized data of Figure 7 suggests a slight roughness decrease; however, these small observed differences are roughly within the instrument resolution of $1 \mu \mathrm{inch}$, and they need further experimentation for validation.

Weight measurements of copper specimens found no significant weight change after jet-impingements for the tested fluids and times. To study possible modifications nondetected by roughness or weight measurements, optical microscopy was conducted for all the specimens after and before treatments. Figures 8 and 9 show microscopy images (for 5000x magnification) for the copper specimens before and after jet-treatments with each corresponding fluid.

Figure 8 allows comparison of before- and after-test images with reference fluid of 50/50\% ethylene glycol and water (magnification: 5000x), without nanoparticles. Before treatment, some limited pitting (circled in "before" image) and machining scratches were observed, while after 112-hour treatment polishing scratches have not been removed, and widespread small-size pitting is observed (some pitting after treatment seems to cluster around some areas (circled in "after" image).

Figure 9 allows comparison of before- and after-test images with nanofluid of $2 \%$ alumina in $50 / 50 \%$ ethylene glycol and water (magnification: 5000x). After 112-hour treatment, polishing scratches were not removed, and preexisting

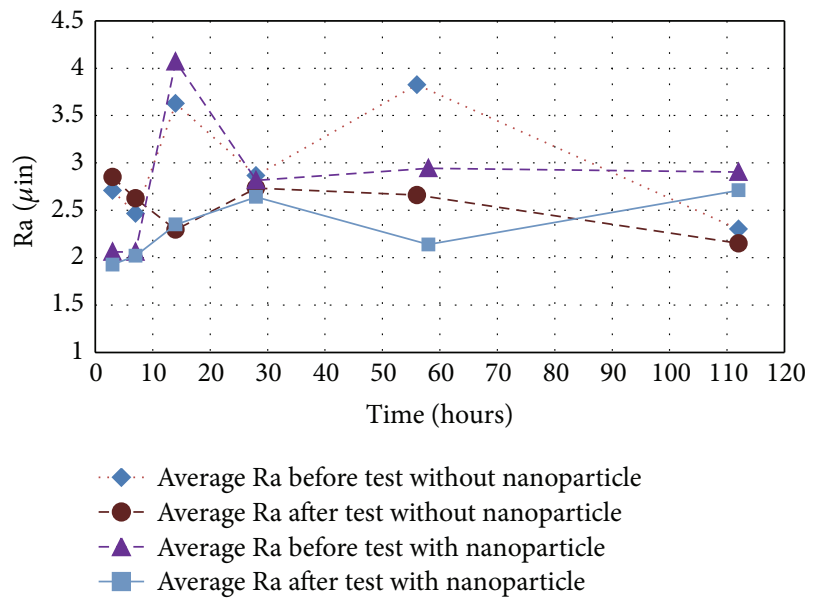

Figure 6: Average Ra roughness for alloy 110 copper before and after 3-, 7-, 14-, 28-, 56-, and 112-hour treatments with the reference fluid of 50/50\% ethylene glycol in water and with nanofluid of $2 \%$ nanoalumina in reference fluid.

pitting (circled in Figure 9) became much larger; some pitting seems to cluster along original scratching lines (circled in Figure 9).

The presented studies show that all tested fluids yield substantial early modifications of the original surfaces, even 


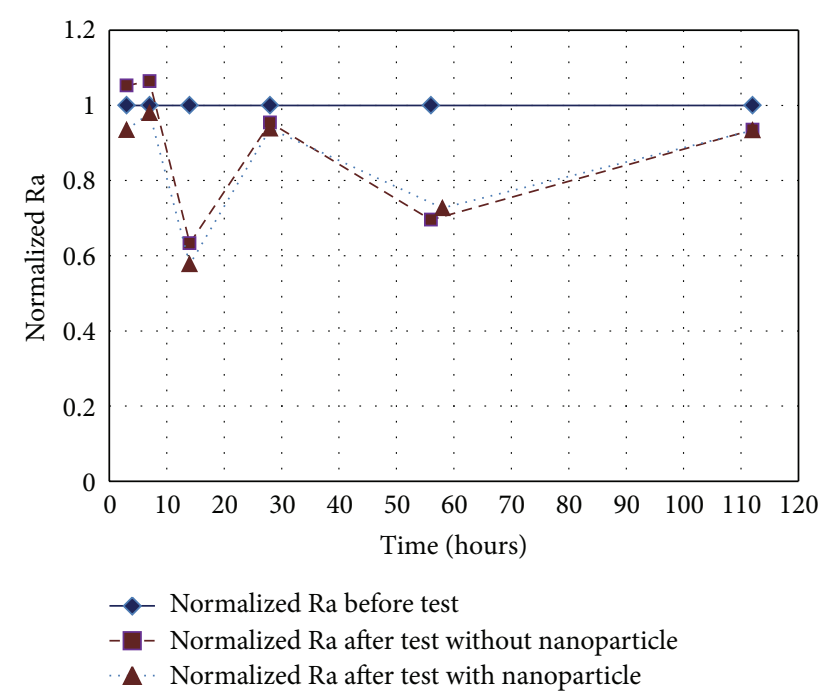

Figure 7: Normalized Ra roughness for alloy 110 copper before and after 3-, 7-, 14-, 28-, 56-, and 112-hour treatments with the reference fluid of 50/50\% ehtylene glycol in water and with nanofluid of $2 \%$ nanoalumina in reference fluid.

for low-speed jet-impingement and for relatively short times (compared to operational times of actual cooling systems). In particular, the microscope imaging studies suggest that the mechanisms of surface change for the employed lowspeed fluid-impact are different from those reported in the literature. The fundamental case of high-speed singleparticle erosion on impacted surfaces is well known [33], and multiple millimeter-size particle impact phenomena have been extensively studied [34-38], where work hardening and subsequent spalling after "incubation period" play important roles in such dry-erosion cases. The observed changes driven by low-speed-fluid of this study, however, seem to relate to mild abrasion and to 1 to 10 micrometer-size pitting erosion.

\section{Conclusions}

The authors developed an instrument to employ a lowspeed jet for the testing of nanofluid interactions with typical cooling-system material surfaces. This research work shows the feasibility of using roughness and removed-material (by weighing) measurements and optical microscopy imaging for assessing the possible early surface changes.

The low-speed tests with a reference fluid of 50/50\% ethylene glycol in water and with the nanofluid obtained by adding $2 \%$ of alumina in such reference fluid allowed the study of surface evolution of polished 3003-T3 aluminum specimens for up to 112 hours of testing. For both fluids Ra roughness values increased (up to eightfold for the longest tested time of 112 hours). The evolution of roughness suggests that cleaning the surface and removing loose material occur during the first three hours of test, while smoothening (removing deeper polishing scratch lines) would proceed within the first 14 hours, followed by increased material erosion after 28 hours of test.
For the 28- to 112-hour interval of jet-impingementtest in aluminum there are no significant differences on the measured roughness values after treatment with the reference fluid (ethylene glycol/water), compared to the same treatments with the 2\%-alumina-nanofluid. But optical microscopy imaging (magnification 5000x) showed different surface-modification mechanisms: while reference fluid completely removed polishing scratches and enlarged original small pitting for the 112-hour test, the 2\%-alumina-nanofluid did not completely remove polishing scratches and it led to widespread small pitting, which seems to cluster along some original scratching lines. Since alumina is fairly chemically inert, material removal in this early surface-modifying mechanism in aluminum should be attributed to mainly mild abrasion mechanisms, with no significant chemical erosion component; these mechanisms are in good agreement with the findings of George et al. [28], which were obtained for titanium-dioxide nanofluid jet-impinged on aluminum.

The same low-speed tests (with reference fluid of 50/50\% ethylene glycol in water, and with the nanofluid obtained by adding $2 \%$ of alumina in such reference fluid), allowed the study of surface evolution of polished alloy 110 copper specimens. The two fluids produced neither significant roughness differences nor significant material removal by weight measurements. But optical microscopy imaging (magnification $5000 \mathrm{x}$ ) showed that both fluids start surface changes on copper. While neither fluid treatment removed the initial polishing scratches, widespread small pitting was observed for the reference fluid in 112 hours, while preexisting pitting became much larger for the $2 \%$-alumina-nanofluid in the same test-time, with some pitting clustering along original scratching lines. The absense of significant scratching-line removal in copper suggests that the observed early surfacemodification mechanism should be attributed to mainly mild erosion, with a likely chemical component. However, further studies are needed to clearly determine all involved mechanisms for the materials and fluids tested. The authors conducted some SEM observations of surfaces; however, because of the relatively large size of the observed surface scratches before treatments and of pitting after treatments (in Figures 4, 5, 8, and 9), SEM images have not been useful to investigate the phenomena.

Studies of nanoparticles attachment to the surfaces require further research. Effects of material heating and cooling (as they may occur in an actual heat-exchanger system) for longer periods are also the subjects of current studies. Relative hardness of the nanopowders compared to that of the impacted surfaces and their work hardening can be factors in the studied phenomena, and they are included in the authors' follow-up current research work.

There are no published studies on the effects of nanoparticle size in erosion rates; the work of Lynn et al. [39] on micrometer-size-SiC-particle slurry erosion of steel found that erosion rates decrease with particle size, but these and other works [40] should not be extrapolated to the nanometer-size scale, because nanosize-particle aggregation and clustering are not yet well-understood, and they seem to be dependent on powder and base-fluid properties. For instance, a recent paper [41] reports substantial aggregation 

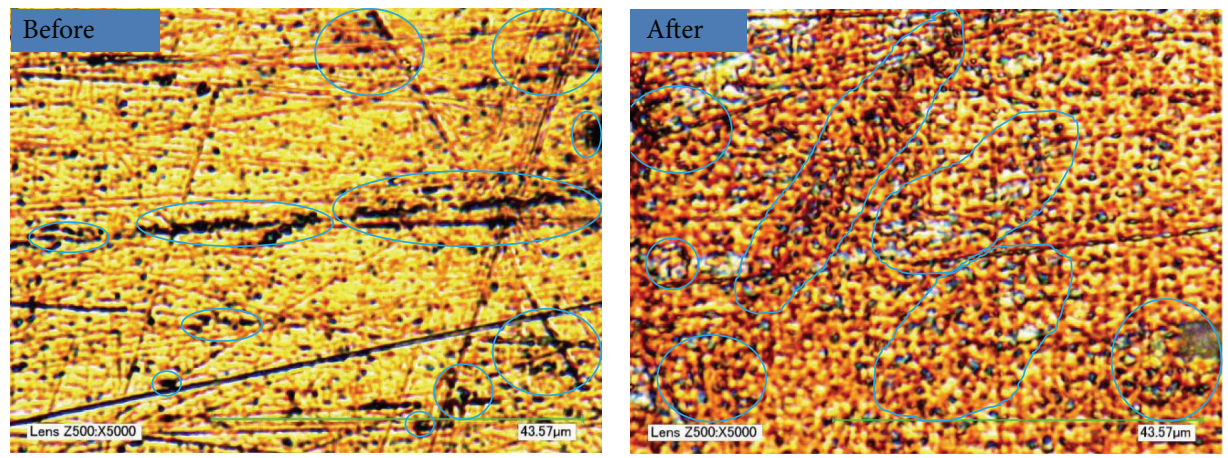

Figure 8: Optical microscopy images of alloy 110 copper before and after (112-hour) test with (reference fluid, without nanoparticles) 50/50\% ethylene glycol/water (magnification: 5000x). Preexisting pitting and seemingly clustered ones after treatment are circled.
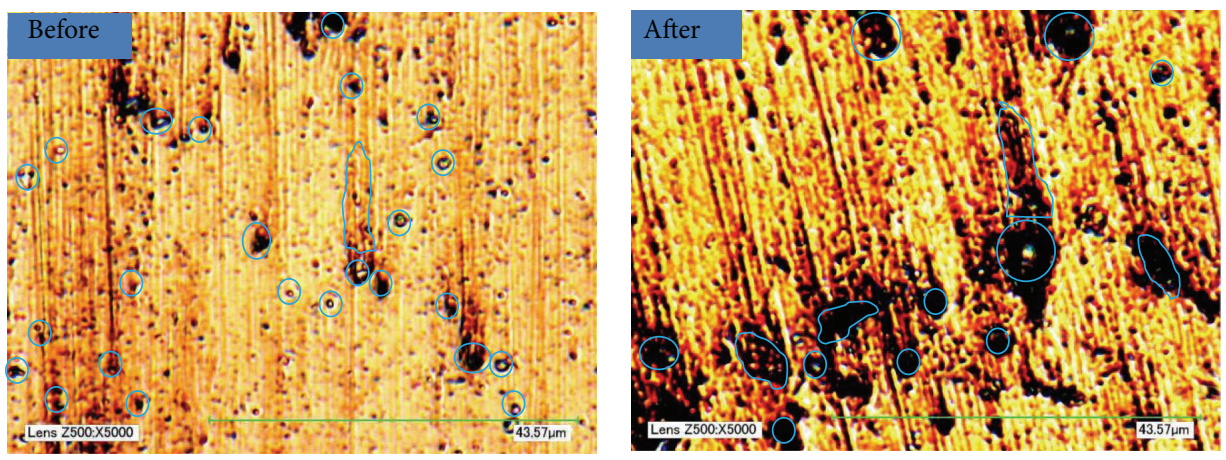

Figure 9: Optical microscopy images of alloy 110 copper before and after (112-hour) test with nanofluid of 2\% alumina in 50/50\% ethylene glycol/water (magnification: 5000x). Preexisting pitting and enlarged ones after treatment are circled.

(up to the micrometer scale) for alpha-alumina-in-water nanofluids, while gamma-alumina-in-water ones present no aggregates (or if any, they would be of much less than micrometer size). Therefore, studies of nanoparticle-size effects in nanofluid erosion require further research.

\section{Conflict of Interests}

The authors declare that there is no conflict of interests regarding the publication of this paper.

\section{Acknowledgments}

The authors gratefully acknowledge support from the Allen E. Paulson College of Engineering and Information Technology, through an undergraduate research grant, and from the Faculty Research Committee, Georgia Southern University, Georgia, USA, through a faculty research seed grant.

\section{References}

[1] S. U. S. Choi and J. A. Eastman, "Enhancing thermal conductivity of fluids with nanoparticles," in Proceedings of the International Mechanical Engineering Congress and Exhibition, Report no.: ANL/MSD/CP-84938, CONF-951135-29, ON: DE96004174, TRN: 96:001707, San Francisco, Calif, USA, November 1995.
[2] S. U. S. Choi, Development and Applications of Non-Newtonian Flows, edited by D. A. Siginer and H. P. Wang, ASME Publisher, 1995.

[3] A. K. Singh, "Thermal conductivity of nanofluids," Defence Science Journal, vol. 58, no. 5, pp. 600-607, 2008.

[4] J. Buongiorno, "Convective transport in nanofluids," Journal of Heat Transfer, vol. 128, no. 3, pp. 240-250, 2006.

[5] K. V. Wong and O. De Leon, "Applications of nanofluids: current and future," Advances in Mechanical Engineering, vol. 2010, Article ID 519659, 11 pages, 2010.

[6] R. Taylor, S. Coulombe, T. Otanicar et al., "Small particles, big impacts: a review of the diverse applications of nanofluids," Journal of Applied Physics, vol. 113, no. 1, Article ID 011301, 2013.

[7] J. A. Eastman, S. U. S. Choi, S. Li, W. Yu, and L. J. Thompson, "Anomalously increased effective thermal conductivities of ethylene glycol-based nanofluids containing copper nanoparticles," Applied Physics Letters, vol. 78, no. 6, pp. 718-720, 2001.

[8] B. C. Pak and Y. I. Cho, "Hydrodynamic and heat transfer study of dispersed fluids with submicron metallic oxide particles," Experimental Heat Transfer, vol. 11, no. 2, pp. 151-170, 1998.

[9] P. E. Phelan, P. Bhattacharya, and R. S. Prasher, "Nanofluids for heat transfer applications," Annual Review of Heat Transfer, vol. 14 , pp. 255-275, 2005.

[10] S. M. S. Murshed, K. C. Leong, and C. Yang, "Investigations of thermal conductivity and viscosity of nanofluids," International Journal of Thermal Sciences, vol. 47, no. 5, pp. 560-568, 2008. 
[11] V. Trisaksri and S. Wongwises, "Critical review of heat transfer characteristics of nanofluids," Renewable and Sustainable Energy Reviews, vol. 11, no. 3, pp. 512-523, 2007.

[12] H. Xie, J. Wang, T. Xi, Y. Liu, F. Ai, and Q. Wu, “Thermal conductivity enhancement of suspensions containing nanosized alumina particles," Journal of Applied Physics, vol. 91, no. 7, pp. 4568-4572, 2002.

[13] R. Prasher, P. E. Phelan, and P. Bhattacharya, "Effect of aggregation kinetics on the thermal conductivity of nanoscale colloidal solutions (nanofluid)," Nano Letters, vol. 6, no. 7, pp. 1529-1534, 2006.

[14] R. Prasher, D. Song, J. Wang, and P. Phelan, "Measurement of nanofluid viscosity and its implications for thermal applications," Applied Physics Letters, vol. 89, no. 13, Article ID 133108, 2006.

[15] J. Chevalier, O. Tillement, and F. Ayela, "Structure and rheology of $\mathrm{SiO}_{2}$ nanoparticle suspensions under very high shear rates," Physical Review E, vol. 80, no. 5, Article ID 051403, 2009.

[16] A. J. Schmidt, M. Chiesa, D. H. Torchinsky et al., "Experimental investigation of nanofluid shear and longitudinal viscosities," Applied Physics Letters, vol. 92, no. 24, Article ID 244107, 2008.

[17] P. Ding and A. W. Pacek, "Effect of $\mathrm{pH}$ on deagglomeration and rheology/morphology of aqueous suspensions of goethite nanopowder," Journal of Colloid and Interface Science, vol. 325, no. 1, pp. 165-172, 2008.

[18] S. K. Das, S. U. S. Choi, and H. E. Patel, "Heat transfer in nanofluids-a review," Heat Transfer Engineering, vol. 27, no. 10, pp. 3-19, 2006.

[19] K. Y. Leong, R. Saidur, S. N. Kazi, and A. H. Mamun, "Performance investigation of an automotive car radiator operated with nanofluid-based coolants (nanofluid as a coolant in a radiator)," Applied Thermal Engineering, vol. 30, no. 17-18, pp. 2685-2692, 2010.

[20] S. M. Peyghambarzadeh, S. H. Hashemabadi, M. S. Jamnani, and S. M. Hoseini, "Improving the cooling performance of automobile radiator with Al2O3/water nanofluid," Applied Thermal Engineering, vol. 31, no. 10, pp. 1833-1838, 2011.

[21] S. M. Peyghambarzadeh, S. H. Hashemabadi, M. Naraki, and Y. Vermahmoudi, "Experimental study of overall heat transfer coefficient in the application of dilute nanofluids in the car radiator," Applied Thermal Engineering, vol. 52, no. 1, pp. 8-16, 2013.

[22] S. K. Saripella, W. Yu, J. Routbort, D. France, and U. Rizwan, "Effects of nanofluid coolant in a class 8 truck engine," SAE Technical Paper 2007-01-2141, 2007.

[23] J. L. Routbort and D. Singh, FY 2008 Annual Progress Report for Advanced Vehicle Technology Analysis and Evaluation Activities and Heavy Vehicle Systems Optimization Program, U.S. Department of Energy, AVTAE Activities and HVSO Program, USA, 2008.

[24] D. Singh, Erosion of Radiator Materials by Nanofluids, Vehicle Technologies-Annual Review, U.S. Department of Energy, Argonne National Laboratory, 2009.

[25] C. T. Nguyen, G. Laplante, M. Cury, and G. Simon, "Experimental investigation of impinging jet heat transfer and erosion effect using $\mathrm{Al}_{2} \mathrm{O}_{3}$-water nanofluid," in Proceedings of the 6th IASME/WSEAS International Conference on Fluid Mechanics and Aerodynamics (FMA '08), Rhodes, Greece, August 2008.

[26] G. P. Celata, F. D’Annibale, and A. Mariani, "Nanofluid flow effects on metal surfaces," Energia, Ambiente e Innovazione, no. 4-5, pp. 94-98, 2011.
[27] G. P. Celata, F. D’Annibale, A. Mariani et al., "Experimental results of nanofluids flow effects on metal surfaces," Chemical Engineering Research and Design, 2013.

[28] G. George, R. K. Sabareesh, S. Thomas et al., "Experimental investigation of material surface erosion caused by $\mathrm{TiO}_{2}$ nanofluid impingement," Journal of Nanofluids, vol. 3, pp. 1-11, 2014.

[29] G. J. Molina, M. Hulett, V. Soloiu, and M. Rahman, "Erosion effects of nanofluids on selected cooling-system materials," in Proceedings of the 3rd International Symposium on TriboCorrosion, P. J. Blau, F. E. Schmidt, D. Drees, and J.-P. Celis, Eds., vol. 1563 of ASTM STP, pp. 47-65, ASTM International, West Conshohocken, Pa, USA, 2012.

[30] G. J. Molina, V. Soloiu, and M. Rahman, "On the surface effects of nanofluids in cooling-system materials," in Proceedings of the Materials Research Society Spring Meeting, vol. 1558 of MRS Online Proceedings Library, Cambridge University Press, San Francisco, Calif, USA, April 2013.

[31] MSDS503, "Custom Brand Antifreeze/coolant," Material Data Safety Sheet, 2008, http://msds.walmartstores.com/ client/document?productid=5f456c08-9657-4abf-afb2-6926434 ce2e7\&action $=$.

[32] "Surface Roughness Measuring Tester Surftest SJ-210 User's Manual," No. 99MB122A, Series No.178, Mitutoyo Corp., Japan.

[33] P. A. Engel, Impact Wear of Materials, Elsevier, New York, NY, USA, 1976.

[34] I. M. Hutchings, "Mechanisms of the erosion of metals by solid particles," in Proceedings of the ASTM Symposium on Erosion: Prevention and Its Useful Applications, W. Alder, Ed., ASTM STP 664, pp. 59-76, ASTM International, West Conshohocken, Pa, USA, 1979.

[35] I. M. Hutchings, "A model for the erosion of metals by spherical particles at normal incidence," Wear, vol. 70, no. 3, pp. 269-281, 1981.

[36] A. K. Cousens and I. M. Hutchings, "A critical study of the erosion of an aluminium alloy by solid spherical particles at normal impingement," Wear, vol. 88, no. 3, pp. 335-348, 1983.

[37] W. A. Brainard and J. Salik, "Scanning-electron-microscope study of normal-impingement erosion of ductile metals," NASA Technical Paper 1609, National Aeronautics and Space Administration Scientific and Technical, Information Office, Lewis Research Center, Cleveland, Ohio, USA, 1980.

[38] P. Veerabhadra Rao and D. H. Buckley, "Time dependence of solid-particle impingement erosion of an aluminum alloy," NASA Technical Paper 2169, National Aeronautics and Space Administration Scientific and Technical Information Branch, Lewis Research Center, Cleveland, Ohio, USA, 1983.

[39] R. S. Lynn, K. K. Wong, and H. M. Clark, "On the particle size effect in slurry erosion," Wear, vol. 149, no. 1-2, pp. 55-71, 1991.

[40] L. Fuyan and S. Hesheng, "The effect of impingement angle on slurry erosion,” Wear, vol. 141, no. 2, pp. 279-289, 1991.

[41] S. A. Angayarkanni and J. Philip, "Role of adsorbing moieties on thermal conductivity and associated properties of nanofluids," Journal of Physical Chemistry C, vol. 117, no. 17, pp. 9009-9019, 2013. 

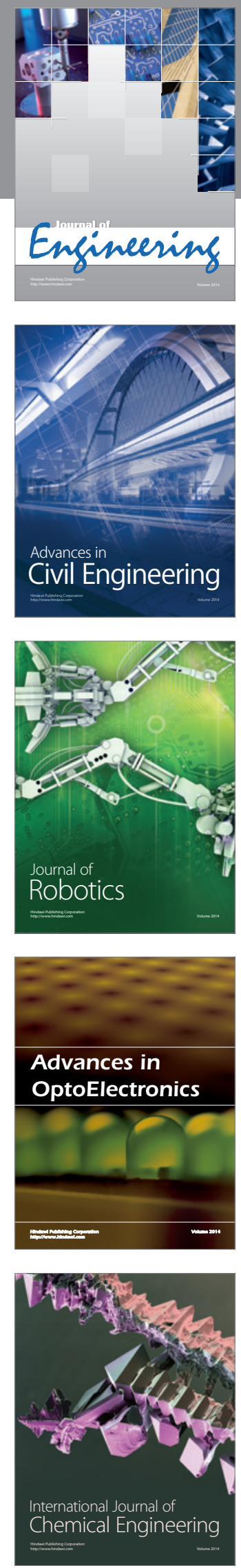

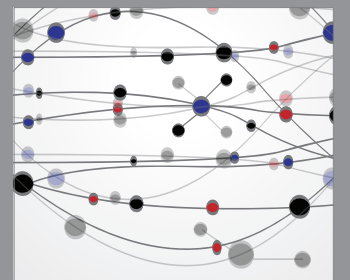

The Scientific World Journal
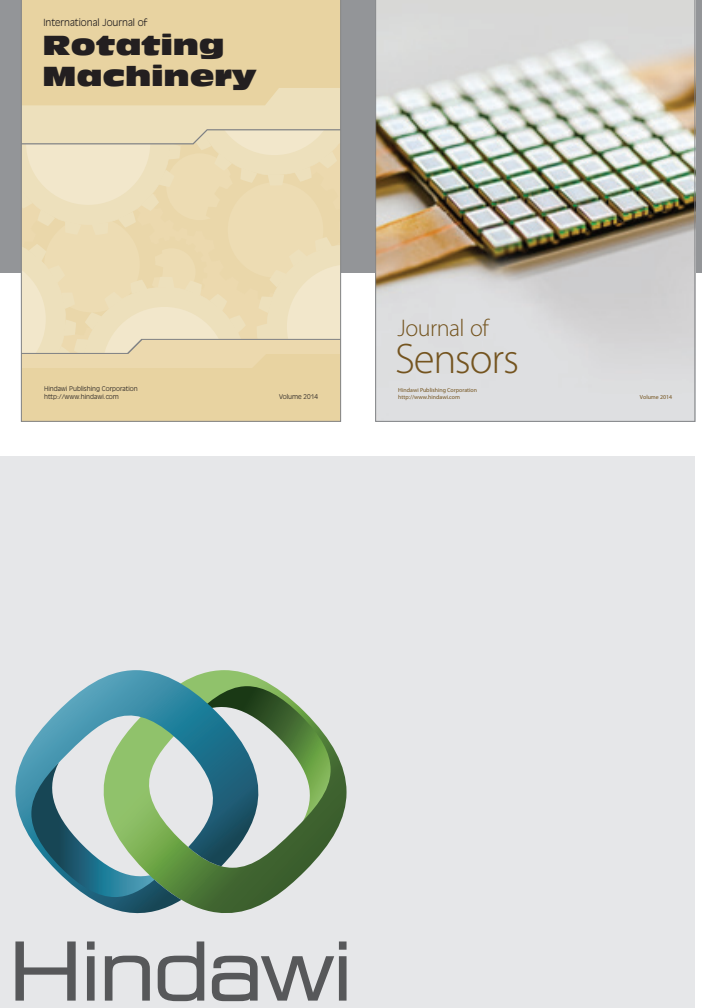

Submit your manuscripts at http://www.hindawi.com
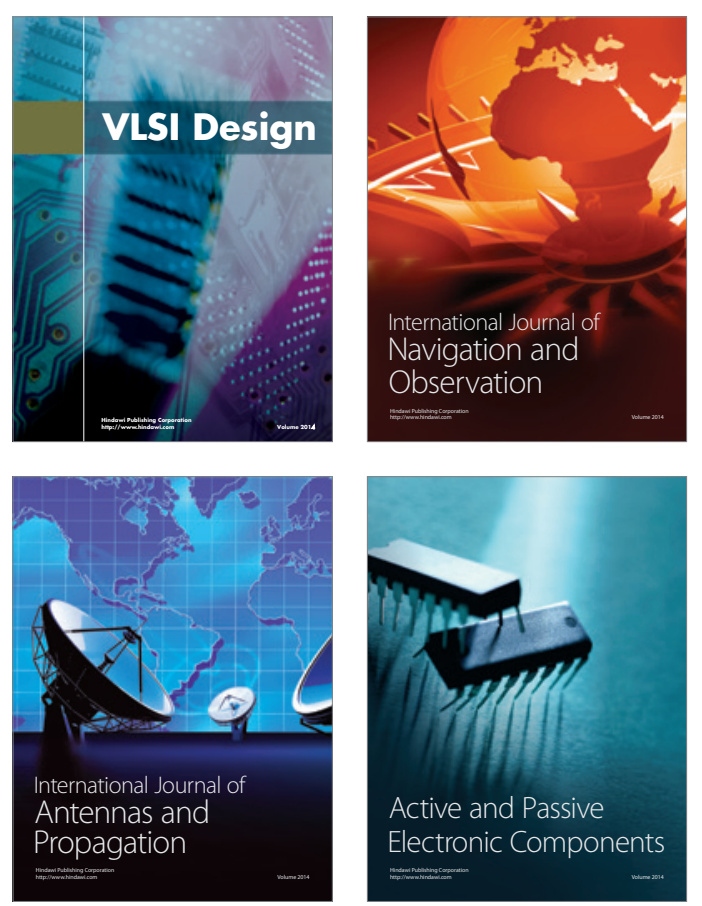
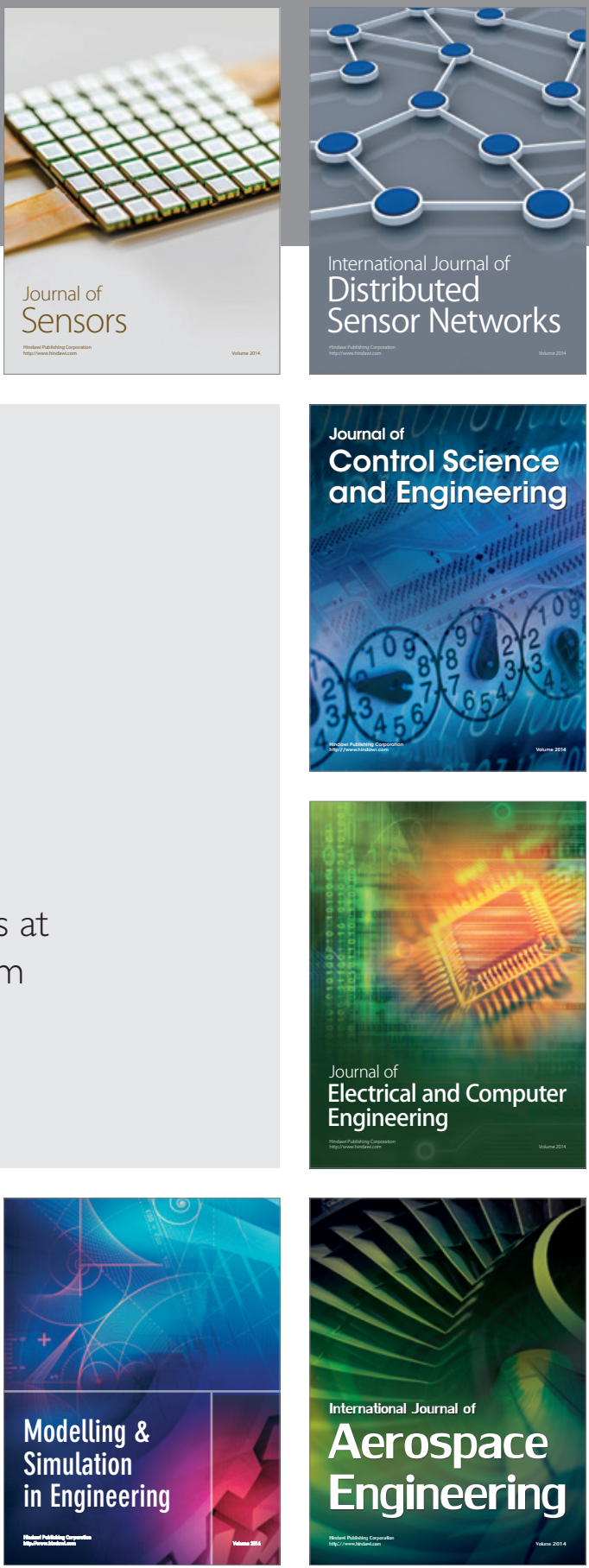

Journal of

Control Science

and Engineering
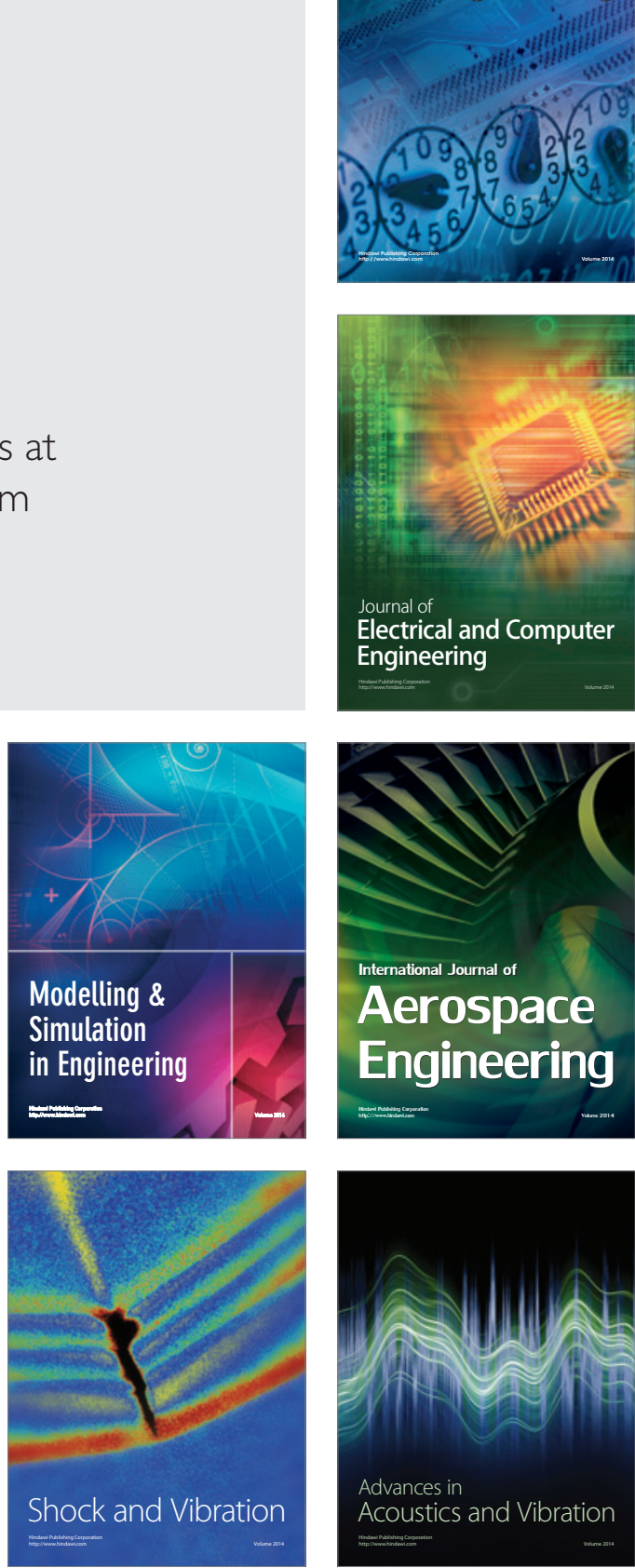